\title{
COMUNICAÇÃO E ESTRATÉGIAS DE CONSUMO NO CONTEXTO DAS WEARABLE TECHNOLOGIES
}

\author{
Communication and consumer strategies in the context of wearable technologies \\ Comunicación y estrategias de consumo en el contexto de las wearable \\ technologies
}

Vicente Martin Mastrocola

Professor de Game Design e Mídias Digitais, ESPM-SP

vincevader@gmail.com

\section{Resumo}

Tendo em vista a centralidade das relações entre comunicação, consumo e tecnologia na contemporaneidade, este artigo examina determinados dispositivos digitais que potencialmente se hibridizam ao corpo humano e que se situam na categoria das wearable technologies. Discutimos como a orquestração de diversos objetos sociotécnicos está reconfigurando o cotidiano e gerando novas possibilidades para pensarmos as materialidades da comunicação e as retóricas do consumo. Neste trabalho, não nos atemos a um device específico; procuramos refletir de maneira ampla sobre diferentes exemplos de integrações entre humano e não-humano, ponderando, mais especificamente, sobre como esse tipo de tecnologia pode servir estrategicamente para relações entre marcas/empresas e seus consumidores.

Palavras-chave: Comunicação e Consumo. Wearable Technology. Cibercultura.

\begin{abstract}
In view of the centrality of relationships between communication, consumption and technology in contemporaneity, the present research project examines certain digital devices which potentially hybridize to the human body and lie in the wearable technology category. We discuss how the orchestration of various socio-technical objects is reconfiguring daily life and generating new possibilities to think the materiality of communications and the rhetorics of consumption. This study does not attain to a specific device. We seek to think, in a broader fashion, different examples of integration between humans and non-humans, considering, among other aspects, how this type of technology can serve strategically to enhance relationships between brand/companies and their consumers.
\end{abstract}

Key words: Communication and Consumption. Wearable Technology. Cyberculture.

\section{Resumen}

En vista de la centralidad de las relaciones entre comunicación, consumo y tecnología en la contemporaneidad, este artículo examina determinados dispositivos digitales que 
potencialmente se hibridizan al cuerpo humano y que se sitúan en la categoría de las wearable technologies. Discutimos cómo la orquestación de diversos objetos sociotécnicos está reconfigurando lo cotidiano y generando nuevas posibilidades para pensar las materialidades de la comunicación y las retóricas del consumo. En este trabajo, no nos restringimos a un dispositivo específico. Tratamos de reflexionar de manera amplia sobre diferentes ejemplos de integraciones entre humano y no humano, ponderando, más específicamente, sobre cómo ese tipo de tecnología puede servir estratégicamente para relaciones entre marcas / empresas y sus consumidores.

Palabras clave: Comunicación y Consumo. Wearable Technology. Cibercultura.

\section{WEARABLE TECHNOLOGIES: DA FICÇÃO PARA A REALIDADE CONTEMPORÂNEA}

Desde os seus primórdios, a ficção científica sempre tratou de fantasiar com avanços tecnológicos mirabolantes que poderiam se tornar realidade em futuros longínquos. Em 1870, Julio Verne narrou as aventuras do Capitão Nemo e de seu submarino Náutilus em Vinte mil léguas submarinas. Na década de 1980, foi lançado o icônico Neuromancer, cuja narrativa se desdobra em uma sociedade na qual existem indivíduos que se conectam a um locus virtual denominado "ciberespaço" (termo cunhado pelo autor, Willian Gibson) por meio de uma sofisticada integração entre cérebro e máquinas. Neste ambiente, o corpo é digitalizado e, no desenrolar da trama, tem-se o questionamento acerca das consequências de se expandir a mente para além dos limites do humano.

Nitidamente inspirados por esta obra, e conjugando-a com outras referências, os irmãos Wachowsky criaram para o cinema a trilogia Matrix, composta pelos longa-metragens Matrix (1999), Matrix Reloaded (2003) e Matrix Revolutions (2003). Os três filmes relatam a luta de um grupo de resistência humana contra a hegemonia de máquinas pensantes conectando a mente em um ambiente virtual futurista, no qual as regras do dito "mundo real" podem ser alteradas e a tirania das máquinas, eventualmente, superada. Dentro desse cenário virtual, humano e máquina se misturam no desenrolar da trama da franquia, que virou um blockbuster dentro do gênero de ficção cult.

Ao observarmos as produções advindas da ficção científica, percebemos que muito do que foi proposto nessa área pouco a pouco vem se tornando parte de nosso dia-a-dia. Dentre as práticas que caracterizam a contemporaneidade, o uso regular de computadores, tablets, smartphones e videogames como partes de um enorme rol de aparatos tecnológicos merece um lugar de destaque. São inúmeros os formatos desses dispositivos, sendo que muitos possuem a capacidade de conexão com a internet e sites de redes sociais. A 
multiplicidade de aparatos e o fato de muitos deles serem conectados online altera, de maneira significativa, o modo como alguns indivíduos experienciam o cotidiano e como determinadas empresas estruturam suas estratégias de marketing e comunicação para marcas, produtos e serviços.

Vale ressaltar que os sofisticados computadores e os atuais gadgets repletos de funcionalidades têm um precursor: o ENIAC (Eletronic Numerical Integrator and Computer), criado na década de 1940, logo após a Segunda Grande Guerra. Segundo McCartney (2001, p.20), esse foi o primeiro computador programável e totalmente eletrônico do planeta. Como se sabe, da data até hoje, os avanços foram significativos e boa parte do mundo se conectou de maneira rizomática ou descentralizada aos computadores e redes digitais de comunicação, sociabilidade e negócios (CASTRO, 2012). A ideia de tal conexão se dá pelo fato de trocas e acessos estarem mais fragmentados em múltiplos aparatos e estruturas que permitem comunicação entre indivíduos.

Arjun Appadurai (1999, p.313) utiliza o termo tecnopanorama para explicitar a configuração fluida da tecnologia em algumas sociedades, descrevendo como ela "se movimenta em alta velocidade através das diversas formas de barreiras anteriormente intransponíveis". Esse mesmo autor também discorre sobre a ideia de midiapanorama (1999, p.315), que diz respeito à "distribuição de capacidades eletrônicas de produzir e disseminar informações" que se encontram atualmente à disposição de um número cada vez maior de grupos privados e públicos em diferentes lugares do mundo. O que o autor propõe ao falar em tecnopanorama e midiapanorama é que estamos imersos em uma realidade repleta de aparatos tecnológicos que permitem que a sociedade crie outras modalidades de agenciamento e modifique a maneira como a informação é distribuída nesse ambiente. Neste sentido, empresas e consumidores passam a se relacionar de uma maneira reconfigurada, pois a economia é afetada por estas transformações e passa a ser uma nova economia global superposta e complexa (APPADURAI, 1999, p.312). Do ponto de vista dos negócios e das estratégias de comunicação, a disponibilidade tecnológica e midiática amplia possibilidades de diálogo de maneira sincrônica e assincrônica entre grupos empresariais e indivíduos/consumidores.

Além de estabelecer laços afetivos entre pessoas, a intensificação do uso de aparelhos computadorizados permite que companhias criem estratégias de vendas de produtos para consumidores. Permite ainda que governos armazenem informações sobre cidadãos em seus diversos bancos de dados. Nesse sentido, empresas se apropriam estrategicamente de e- 
mails e números de celulares de seus consumidores para enviar mensagens com ofertas e publicidade de produtos. Órgãos governamentais elaboram softwares para que que cidadãos façam suas declarações de imposto de renda e pagamentos de contas e tributos. Indivíduos se comunicam com seus pares, com fins profissionais ou pessoais, por meio de aplicativos de mensagens em seus smartphones e programas de e-mail. Notamos um processo amplo de vigilância nesse contexto. Lacerda (2006, p.186) observa que um nítido e constante processo de reconfiguração dos processos de comunicação se faz presente na contemporaneidade devido ao intenso uso de objetos tecnoinformacionais (celulares, video games, smartphones, tablets etc) que o autor classifica como "próteses midiáticas".

Lacerda (2011, p.128) também ressalta que tais "próteses midiáticas passam a participar mais da produção de sentidos nos processos de configuração do ambiente". Colocado de outro modo, na inter-relação entre tecnologia e comunicação, articulam-se novas maneiras de nos relacionarmos com o ecossistema comunicacional permeado por aparatos de todo o tipo. A ideia de um ecossistema que passa a preencher o cotidiano com diferentes tecnologias é uma metáfora central para compreendermos determinados processos de comunicação e consumo (material e simbólico) na contemporaneidade. Com base nas palavras de Scolari (2008, p.26), podemos afirmar que um ecossistema comunicacional pode ser entendido como "um conjunto de intercâmbios, hibridações e mediações dentro de um entorno onde confluem tecnologias, discursos e culturas".

Em um cenário em que ocorre um grande número de interações entre indivíduos e dispositivos tecnológicos, a relação com um ecossistema é bastante pertinente. Tal qual um acidente geológico que muda o curso de um rio e pode afetar o cotidiano da fauna e da flora daquele ambiente, a introdução de um novo aparato tecnológico (como um smartphone, por exemplo) também pode afetar o cotidiano de determinados indivíduos que passam a utilizar a tecnologia, alterando processos de seu dia a dia.

Estabelecendo um paralelo com o exemplo anterior, podemos imaginar uma empresa que distribui seus produtos em pontos de venda físicos e que passa a vendê-los na internet. Neste caso, tal empresa também modifica a maneira como se relaciona com consumidores e lojistas. Quando o site de vendas online é introduzido na equação, toda uma cadeia de distribuição, formação de preços, pagamentos de impostos, atendimento ao consumidor e legislação é alterada em um complexo processo que envolve, muitas vezes, um grande número de profissionais especializados em cada parte do projeto. 
Nesse ambiente de confluência entre humanos e telas, estudamos neste artigo a provocante categoria das wearable technologies. ${ }^{1}$. A WT é um tipo de tecnologia predominantemente digital ${ }^{2}$ que se manifesta em um grande número de formatos e que, potencialmente, se hibridiza ao corpo do usuário, gerando diversas configurações entre humano e não-humano. Tal tecnologia também é apropriada por marcas e empresas que começam a utilizar determinados aparatos como ferramentas estratégicas em suas campanhas de comunicação e marketing, como foi o caso da Nike ao lançar a pulseira inteligente Nike+ Fuelband, em 2012, como esforço integrante de sua campanha de publicidade mundial ${ }^{3}$. Tal device serve como medidor de performance para praticantes de exercícios físicos e opera como plataforma para propaganda de produtos da empresa.

Atualmente, há uma variada gama de produtos da categoria wearable, cujas funcionalidades se voltam para o campo de atividades esportivas e a área da saúde. Por conta da "leitura" de dados corporais por meio de sensores, grande parte dos aparatos que se encontram no mercado concentram seus esforços dentro dessas searas. Estes dispositivos serão o foco deste artigo.

Os produtos apresentados na Figura 1, a seguir, exemplificam o que discutimos. À esquerda, vemos alguns exemplares da pulseira Runtastic Orbit. Este device analisa distâncias percorridas pelo usuário, calcula o tempo gasto no percurso e monitora os batimentos cardíacos para informar se é conveniente acelerar ou diminuir o ritmo de uma corrida. $\mathrm{O}$ colete Hexoskin avalia a quantidade de calorias gastas durante o exercício físico e monitora também os padrões de sono se o usuário vestir o aparato enquanto dorme, fornecendo feedback por meio de um aplicativo de smartphone. Por último, vemos o Jabra Sport Pulse, um par de fones de ouvidos que fornece áudios com instruções para sequências de exercícios e aciona músicas (mais lentas ou com ritmo mais acelerado) de acordo com o monitoramento da pulsação de seu usuário, que vai se modificando durante a realização da prática esportiva.

\footnotetext{
${ }^{1}$ Neste trabalho, no decorrer do texto, frequentemente iremos utilizar a abreviação WT para nos referirmos às wearable technologies. Também utilizaremos "tecnologia vestível" para tratar do tema.

${ }^{2}$ É importante ressaltar que aparatos que pertencem à categoria de wearable technologies utilizam diferentes tipos de sensores para materializarem suas funções e enviam dados para variadas plataformas. A rigor, há processos fundamentados por sistemas de processamento de dados digitais e mecânicos/analógicos.

${ }^{3}$ No entanto, há experimentos com wearables que são anteriores ao produto da Nike, conforme aponta Donati (2005) em estudo pioneiro sobre o "computador vestível”.
} 
Figura 1- Exemplos de formatos de wearable devices

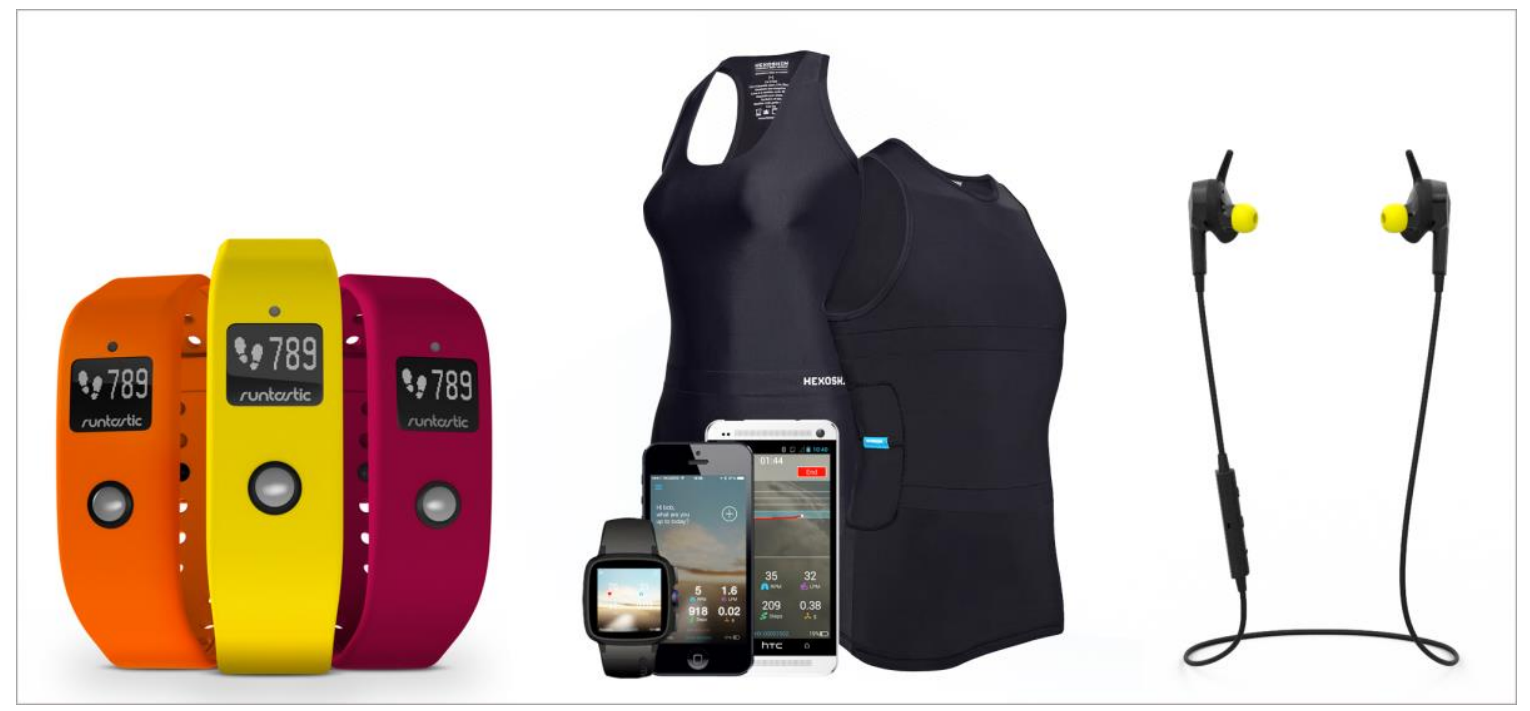

Fonte: The New York Times.

Tais aparelhos que monitoram funções corporais e transformam a atividade física em informações digitais começaram a gerar um interessante fenômeno: o surgimento de indivíduos obcecados pela "dataficação" de seus corpos e quantificação do self. Logo, se há uma gama de indivíduos ávidos por tais processos de metrificação de performances, há também uma série de empresas interessadas em monitorar e capturar dados dos mesmos com o intuito de usarem em prol de suas marcas, produtos e serviços. Notamos a apropriação de uma tecnologia emergente, uma interface humano/não-humano que passa a desempenhar funções dentro do universo de business. Seria inocente entender que este cenário é apenas priveliado por questões de cunho tecnológico. Entendemos que tal ecossistema é permeado por complexos processos de comunicação e consumo, que iremos discutir no tópico a seguir.

\section{COMUNICAÇÃO, CONSUMO E WEARABLE TECHNOLOGIES}

O consumo se tornou um tema presente nos trabalhos de inúmeros pesquisadores contemporâneos. Autores como Featherstone (1995), Slater (2002), McCracken (2003) e García Canclini (2005), entre outros, discutem o assunto a partir de diferentes disciplinas e nos ajudam a entender o consumo como um elemento basilar da cultura contemporânea. Neste artigo, o consumo não está restrito ao ato de adquirir produtos e bens materiais; também está ligado ao aspecto simbólico, que é determinante quando tratamos de marcas. Neste sentido, as wearable technologies devem ser entendidas como objetos sociotécnicos que se materializam no formato de pulseiras, relógios, coletes, colares etc, porém sem esquecer que carregam em 
si uma série de atributos simbólicos que estarão intimamente ligados às marcas/empresas que as produzem. A pulseira Nike+, mencionada no tópico anterior, é adquirida como um bem material pelos consumidores, mas possui uma marca esportiva (Nike) endossando a experiência e legitimando o uso do produto no campo de fitness e das atividades esportivas.

Tais elementos sociotécnicos fabricados por empresas que utilizam tecnologia de ponta passam a fazer parte da vestimenta cotidiana de muitos de seus usuários. Neste contexto, elementos humanos e não-humanos se relacionam mediados por marcas que estão presentes nos devices, aplicativos e produtos. Um relógio que avisa quando o corpo está no limite da exaustão e precisa repor líquidos, um colete que analisa o sono e informa maneiras de dormir com mais qualidade ou uma pulseira que metrifica o desempenho em práticas esportivas e envia sugestões de calçados para uma melhor performance são alguns exemplos que podemos trazer para demonstrar estas novas articulações entre elementos humanos e nãohumanos no cotidiano.

Oferecer um determinado tipo de produto baseado na performance monitorada de um usuário é uma das facetas que a tecnologia possibilita, mas é preciso lembrar que as marcas e empresas também objetivam que estes indivíduos compartilhem a experiência de uso em redes sociais digitais de que participam. Mais do que oferecer produtos sob medida, essas empresas anseiam por que seus usuários façam propaganda de sua marca ou produto de maneira voluntária e gratuita.

Em um primeiro momento, o cenário de conexão entre o corpo de usuários e aparatos mediados por marcas pode, erroneamente, ser entendido como um ambiente de alienação e consumismo fútil. Mas vale lembrar que consumo, nesse texto, não deve ser confundido com o consumismo voraz, a mera e inconsequente aquisição desenfreada de produtos. Na discussão aqui proposta, o consumo deve ser entendido como

o resultado de um conjunto de práticas sociais e culturais fortemente relacionados às subjetividades dos atores e ao grupo social ao qual pertencem. Imersos nessas culturas do consumo, nós criamos identificações, construímos identidades, reconhecemos nossos pares e somos reconhecidos socialmente. Quando consumimos, não estamos apenas admirando, adquirindo ou utilizando determinado produto ou serviço. Estamos comunicando algo e criando relações com tudo e todos os que estão à nossa volta (CASTRO, 2014, p.60).

Castro (2014, p.60) entende que o consumo é um campo plural e que hoje "não seria correto falarmos em cultura, mas culturas do consumo". Corroborando essa ideia, Sassatelli 
(2010, p.193) destaca que as lógicas de consumo que permeiam essas culturas geram uma miríade de consumidores que compram, usam, estocam, mantêm, gerenciam e fantasiam com mercadorias, ainda que se possa questionar até que ponto realmente se concebem como consumidores enquanto executam essas variadas atividades no dia a dia.

O consumo está impregnado no cotidiano. Consumimos produtos, mas também consumimos conteúdos, ideias, simbolismos e imagens. Retomando Castro (2014), o consumo é plural ou multifacetado porque está presente em diferentes situações que nos cercam no dia a dia. Consumimos não somente quando compramos algo em uma loja, mas quando navegamos na internet ou nos movimentamos pela paisagem urbana.

O surgimento das plataformas móveis conectadas à internet e o grande número de telas/devices conectados em rede ajudam a multiplicar as possibilidades de consumo nos tempos em que vivemos. E reforçamos que o consumo, nesse sentido, é amplo não somente porque podemos consumir produtos por intermédio de um e-commerce, mas porque podemos consumir textos, imagens, ideias, vídeos, sons e todo tipo de conteúdo que se encontra disponível nessas plataformas.

Neste cenário multifacetado, também podemos entender o consumo como o "conjunto de processos socioculturais em que se realizam a apropriação e os usos dos produtos" (CANCLINI, 2005, p.77). Ou seja, o consumo é aqui entendido como algo muito maior do que o ato de adquirir um bem. É um processo que deflagra pertencimento social e que insere indivíduos em círculos sociais específicos, repletos de múltiplos significados.

Neste contexto, refletindo acerca das wearable technologies, seria inocente afirmar que, quando um consumidor adquire uma pulseira Fitbit ou um $i$ Watch, está simplesmente buscando um bem com um fim que se encerra nele mesmo. Ao escolher uma marca e não outra, uma smartband ou um smartwatch, ao dedicarmos tempo de pesquisa para avaliar as características mais interessantes de determinado device e ponderar sobre questões de custo/benefício, notamos um processo que transcende a simples compra da mercadoria. Há um entrelaçamento complexo de pertencimento social e inclusão em um grupo específico de indivíduos.

Certos indivíduos de uma sociedade utilizam a linguagem dos bens com objetivo de se integrar a núcleos sociais específicos ou de ser aceitos em determinados nichos de consumo (MCCRACKEN, 2003, p. 46). No caso das tecnologias vestíveis, não é diferente: notamos que há um entrelaçamento entre os objetos tecnológicos e os consumidores que começam a fazer parte de um grupo de usuários de devices vestíveis. Esses indivíduos, por meio do 
consumo das WTs, passam a compartilhar um elemento em comum e fazer parte de um ambiente de consumo mediado por certas empresas e marcas. Tais objetos se conectam à internet, a outros usuários, apresentam conteúdos para os utilizadores e atuam como plataformas midiáticas. Há múltiplos usos e várias maneiras de pertencer a núcleos sociais por intermédio deles.

É importante ressaltar que, no cruzamento entre comunicação, consumo e tecnologia, prevalecem as lógicas da sociedade conectada, do ciberespaço e da multiplicidade de aparatos ligados à internet. Neste artigo, seguindo o raciocínio de Lemos (2002, p.137) estamos observando plataformas midiáticas

que coletam, manipulam, estocam, simulam e transmitem os fluxos de informação criam uma nova camada que vem a se sobrepor aos fluxos materiais que estamos acostumados a receber. $\mathrm{O}$ ciberespaço é um espaço sem dimensões, um universo de informações navegável de forma instantânea e reversível. Ele é, dessa forma, um espaço mágico, caracterizado pela ubiquidade, pelo tempo real e pelo espaço não-físico.

Diante deste ambiente de conexão multiplataforma, percebemos que também se multiplicam (e são reconfiguradas) as possibilidades de comunicação e consumo. Na era préinternet, por exemplo, para que um indivíduo fosse impactado por comunicação publicitária da marca Nike, ele precisaria estar diante de uma vitrine, assistir a um comercial de televisão, se deparar com um anúncio da empresa etc.

Com a internet, a Nike passa a dispor de novas maneiras de estabelecer contato com este consumidor. Busca adquirir o e-mail deste para enviar-lhe promoções, oferece a possibilidade de comprar online e envia informações sobre esporte na forma de newsletters digitais.

Com a chegada de uma plataforma móvel como os smartphones ou os aparelhos de tecnologia vestível, a Nike passa a ter mais um canal para trabalhar com seu público, como ensina Lemos na citação anterior. De certa maneira, o ciberespaço e os diversos canais digitais que surgem colaboram para ampliar o escopo estratégico da marca, que passa a buscar atingir um número maior de consumidores. Mais recentemente, vimos a Nike investir em seu próprio wearable device seguindo a mesma linha de raciocínio em que a marca vai atualizando as maneiras de atingir seu consumidor por meio de mensagens de cunho publicitário. 
Lemos (2015, p.31) também defende que uma compreensão da cultura contemporânea, especificamente da cultura digital, exige o entendimento de que os dispositivos tecnológicos não devem ser reconhecidos como isolados/fechados, mas como pontos de associações que agem sobre humanos e não-humanos em um cenário de constantes vinculações.

Ao observarmos os devices vestíveis como os que foram apresentados na Figura 1, percebemos que, mais do que aparatos dotados de sofisticação tecnológica, tratam-se de elementos de associação que ligam o corpo do usuário a um aplicativo, um indivíduo a outro em um site de rede social, uma marca a uma rede de consumidores.

No caso da Nike, os ideais de superação esportiva e vitória sempre foram divulgados nas campanhas da marca, mas, atualmente, tais ideais estão presentes em muitas outras plataformas midiáticas. O que antes era propagandeado em rádio, cinema, jornal, televisão e revista, hoje ganha alcance em smartphones, sites, redes sociais, wearable devices, games e vídeos de YouTube, por exemplo.

É notável que o cenário de comunicação e consumo seja alterado sobremaneira pela disponibilidade tecnológica. Conforme lembra Braga (2013, p.157), até um tempo não muito distante, enxergava-se a comunicação como algo matemático, uma passagem de A para B observando-se a codificação na partida e a decodificação na chegada. Comunicar seria garantir essa passagem e "tudo que levasse a transformações seria ruído". Hoje, há outra visão sobre o tema: "perante os 'códigos' da mídia, os receptores comparecem reinterpretando as mensagens, e não simplesmente decodificando" (BRAGA, 2013, p.157).

O cruzamento entre o tecnológico e o humano gera interações diferenciadas no cenário contemporâneo, afetando tanto os processos de comunicação como os de consumo. Lévy (1996, p. 20) argumenta que a intensa virtualização - ou o acesso às plataformas conectadas à internet - do mundo ao redor gera a reinvenção de uma cultura nômade, não por uma volta ao período paleolítico nem às antigas civilizações ancestrais, mas por dar origem a um meio de interações sociais em que as relações se reconfiguram em escala e velocidade mais amplas. Compramos produtos com um clique e os recebemos no conforto do lar. Compartilhamos onde estamos, com quem estamos e o que estamos fazendo com três cliques na tela de um smartwatch. A velocidade e a escala de como os processos comunicacionais e de consumo ocorrem são alteradas significativamente nesse ambiente.

Uma vez apresentadas algumas das intersecções entre comunicação, mídia, consumo e tecnologia vamos observar a seguir um caso prático em que estes diferentes aspectos se 
mesclam para que uma empresa promova sua marca utilizando um werable device como transmissor de mensagens de marca.

\subsection{Um breve estudo de caso: o uso de wearable technology em uma campanha da marca} Nike

Não por acaso, citamos algumas vezes neste artigo a marca Nike. A empresa foi pioneira no lançamento de uma smartband esportiva e já utilizou tal produto em ações promocionais da marca. Iremos discutir neste tópico Um exemplo a ação publicitária "bid your sweat" ${ }^{\prime 4}$, criada pela marca $\mathrm{Nike}^{5}$ em 2012 para os usuários da pulseira Nike+ Fuelband. Nessa ação, as distâncias percorridas pelos usuários se transformavam em pontos para serem apostados em um leilão online de produtos da marca. Cada metro percorrido gerava uma "moeda" virtual para engajar o consumidor em uma experiência com a marca. Nesse exemplo, a pulseira se torna mediadora entre o consumidor, a marca e a ação promocional envolvendo produtos esportivos.

No contexto dessa experiência em rede que envolve um produto tecnológico, usuários e uma marca, é importante discutirmos um ponto fundamental: a Nike, e possivelmente todas as marcas que estão se servindo de wearable technologies, não objetiva somente ofertar produtos ou fazer promoções por meio destes devices.

Há um aspecto importante a ser discutido, que é o fato de que os usuários destes gadgets tecnológicos podem, potencialmente, utilizar suas redes sociais para compartilhar o conteúdo gerado na experiência com a marca. As opções de compartilhamento de performance (seja ela esportiva ou não) em redes sociais digitais como Facebook, Twitter e Instagram, também são um aspecto estratégico em que as marcas se baseiam para lançar esse tipo de produto.

Um utilizador da Nike+ Fuelband, ao expor, por exemplo, sua rotina diária de quilômetros percorridos em corridas e melhorias de desempenho esportivo no Facebook, está compartilhando uma informação que, no site de rede social, é exibido com a marca Nike em destaque. Nesse caso, temos um consumidor que adquiriu o produto wearable e, de certa maneira, se tornou um potencial vetor de propaganda da marca em sua rede de contatos no ambiente digital. Sem contar o fato que produz dados que são monitorados pela empresa.

\footnotetext{
${ }^{4}$ Em uma tradução livre, "aposte seu suor".

${ }^{5}$ Um vídeo da ação está disponível na URL < https://www.youtube.com/watch?v=5Zhsuh7ba9Q>. Acesso em 1/7/2017.
} 
Outro ponto que merece nossa atenção diz respeito às inúmeras possibilidades de monitoramento de dados dos seus consumidores, a que empresas como Nike, Apple e Google passam a ter acesso direto. A impressão de vigilância é inevitável. Tais companhias, com os devices vestíveis, podem invadir a privacidade de cada consumidor por meio dos aparatos que esses utilizam. Entendemos que os dispositivos do campo da WT deflagram uma grande possibilidade de geração de dados digitais que passam a fazer parte das fontes que alimentam o que convencionou-se chamar big data ${ }^{6}$.

Com este breve exemplo apenas começamos a esquadrinhar as diversas possibilidades que as WTs oferecem em termos de estratégia de comunicação, consumo e monitoramento. De certa forma, entendemos que as empresas ainda têm um longo caminho para entender como estas tecnologias podem desenvolver laços mais fortes com seus consumidores.

\section{CONSIDERAÇÕES}

As inquietações em relação ao universo da tecnologia e as intricadas relações que este possui com o campo da comunicação, da mídia e do consumo foram os motivadores principais desse artigo. Os processos de midiatização a partir da hibridização humano/nãohumano por intermédio das wearable technologies amparados por marcas e produtos têm sido discutidos mercadologicamente, midiaticamente e academicamente com frequência relativamente mais ampla, o que sinaliza a importância que a reflexão sobre o assunto passou a adquirir no cenário contemporâneo permeado de inúmeros atores atuando em complexas redes. Estudar a magnitude completa destes ecossistemas é uma tarefa praticamente impossível para um artigo; por isso, reconhecemos os limites que atingimos nas análises aqui propostas.

Diferentes atores (humanos e não-humanos) se conectam nestes processos e é importante ressaltar que esses complexos contextos digitais "se apresentam como ambientes relacionais híbridos ao permitirem múltiplas interações, simultaneamente, com diferentes

\footnotetext{
${ }^{6}$ Sobre esse tema, Kerchove (2015, p.4) afirma que o "big data está ainda na infância" e pode ser percebido como uma colossal acumulação de dados na qual pouco proveito está sendo tirado. Para o pesquisador, ainda falta uma maturação das técnicas de pesquisa online para termos informações mais complexas e eficazes desse ambiente. Kerchove (2015, p.4-5) pondera ainda que, atualmente, deixamos "pistas" sobre quem somos nos dados que compartilhamos em sites de redes sociais, aplicativos, aparatos vestíveis etc, e questiona o quanto é possível preservar de nossa privacidade nesse contexto.
} 
tipos de copresença sobrepostos ao contexto imediato que é determinado pela posição geográfica dos corpos” (NEJM, 2016, p.234). Usuários acessam e compartilham conteúdo em movimento por meio de seus aparatos tecnológicos, mas também deixam traços digitais de cada operação realizada no cenário cotidiano. Tais traços se espalham a cada acesso devido ao uso de um aplicativo de smartphone baseado em geolocalização, ao conectar um wearable device a um site de rede social, ao fazer uma transação bancária ou utilizar um bilhete eletrônico de transporte público. Nejm (2016, p.230) argumenta que a naturalização das tecnologias digitais no cotidiano mediando relações interpessoais está gerando uma gigantesca quantidade de dados que se transformam em rastros de inúmeros indivíduos. Tais rastros digitais "refletem aspectos do self", ou seja, aspectos pessoais dos usuários e, grande parte deles, estão disponíveis para acesso de outros usuários, empresas e seus algoritmos (NEJM, 2016, p.230-231). São dados gerados por aplicativos, softwares, sites de redes sociais e sistemas de pagamento eletrônico.

Os mesmos dados que são gerados nestas plataformas também fluem por meio delas e reconfiguram a maneira com que trabalhamos, socializamos, jogamos, praticamos exercícios, nos alimentamos e conhecemos o mundo. Tais dados, neste contexto, são agenciadores de uma série de processos; principalmente quando são analisados e recombinados por algoritmos e sistemas que podem influenciar aspectos econômicos, políticos e sociais (mesmo que, muitas vezes, sem consentimento das partes envolvidas).

O conjunto de informações privadas emitidas pelos usuários por meio de seus devices digitais gera um "registro integrado das exposições voluntárias e involuntárias, transmitidas e emitidas" que compõem o que pode ser considerado um meta-self, um conjunto de rastros que permite que algoritmos/sistemas de empresas definam que mensagens/conteúdos serão apresentados para determinadas audiências (NEJM, 2016, p.229). Quanto maior o acesso a aplicativos, sites e sistemas por meio de devices digitais conectados em rede, maior a quantidade de dados/rastros gerados. Consequentemente, maiores as chances de certos grupos se apossarem destes dados para interesses de business e marketing, dentre outros. Entendemos que, neste cenário, controlar o que será compartilhado ou quais rastros dos usuários serão passíveis de ser monitorados/encontrados é um fator bastante obscuro. Há uma monetização dos nossos rastros digitais que as empresas negam em expor de maneira clara para os consumidores.

Inegavelmente, a monitoração do self está gerando uma alta quantidade de traços que, normalmente, estão ocultos. É possível observar alguns dados de performance em 
aplicativos e sites de redes sociais, mas não fica claro que outros dados estão sendo capturados e se estes estão seguros ou nas mãos de grupos empresariais, governos ou, até mesmo, criminosos (RETTBERG, 2014, p.79). Considerando que diferentes aparelhos com conexão com a internet podem monitorar dados de seus usuários, como televisores, videogames, brinquedos etc, já se discute que governos precisam criar legislações mais rígidas em relação à captura e utilização de dados de usuários ${ }^{7}$.

A partir das ideias de rastros digitais que geram um meta self e da quantificação do self, outra consideração importante a ser feita é em relação ao imperativo de estar conectado às redes de comunicação sociabilidade e negócios (CASTRO, 2012). Além da necessidade de uma presença pública, tem se tornado mandatório em certos núcleos sociais a existência de uma presença digital constante. O crescente número de usuários nestas redes está gerando reconfigurações drásticas quando tratamos da interface entre comunicação, mídia, consumo e tecnologia.

Nesse sentido, entendemos que as WTs buscam estar presente grande parte do dia em contato com seus usuários, conquistando-os com conteúdos trabalhados para se tornarem relevantes. Rastrear dados, conhecer hábitos de consumo, locais por onde transita o consumidor e com quem ele compartilha conteúdo parece ser um ponto nodal na estruturação de mensagens que visam a atingir/seduzir estes indivíduos para que eles se engajem em uma experiência mais imersiva com a marca.

As questões dos rastros, da quantificação do self e do monitoramento por parte de certas corporações remetem à ideia de centralidade da comunicação e do consumo na experiência de mundo. Também vale ressaltar que essas questões estão diretamente ligadas à hipersaturação de mensagens mercadológicas no ecossistema comunicacional contemporâneo.

As tecnologias vestíveis estão começando a ganhar um espaço maior não só na mídia especializada em tecnologia ou nas mãos de grandes grupos como Google e Nike, mas também em pontos de venda e espaços comerciais convencionais. Na loja Best Buy, localizada na cidade de Montreal (Canadá), por exemplo, já existe uma área exclusiva para a venda de wearable devices que leva o curioso nome de "techno prêt-à-porter" ${ }^{8}$. Nessa sessão da loja (vide Figura 2), é possível encontrar smartwatches, pulseiras inteligentes para fitness, roupas com sensores, fones de ouvido, acessórios de moda etc.

\footnotetext{
7 Conforme reportagem How we sold our souls - and more - to the internet giants. Disponível em: $<$ https://www.theguardian.com/technology/2015/may/17/sold-our-souls-and-more-to-internet-giants-privacysurveillance-bruce-schneier >. Acesso em: 1/7/2017.

${ }^{8}$ Em uma tradução livre do francês: "tecnologia pronta para vestir".
} 
Figura 2 -Setor de wearable technology da loja Best Buy (Montreal; Canadá)



Fonte: Foto de Clarisse Setyon ${ }^{9}$.

Essas reconfigurações que estamos vivenciando estão alterando a maneira de fazer comunicação mercadológica de muitas companhias, sendo que, nesse artigo, demos ênfase para as empresas que se utilizam de aparatos vestíveis em seus portfólios de produtos na tentativa de capturar dados de consumidores para enviar mensagens de publicidade a partir dos devices.

Entendemos que certas empresas focam seus esforços em lançar produtos como os wearable devices por conta da necessidade mercadológica de criar publicidade em novos formatos e/ou no esforço de criar publicidade como conteúdo. A hipersaturação de mensagens de marketing na atualidade impulsiona determinadas companhias a introduzir suas marcas em meio a experiências cotidianas, como vimos com os gadgets Jabra Sports Pulse, iWatch e Nike+ Fuelband.

Cada novo device wearable lançado no mercado chega com um rol de novas funções e integrações que explora com mais intensidade o corpo e os rastros digitais do usuário. Mais

\footnotetext{
${ }^{9}$ Imagem enviada para o autor em 03/05/2016. Clarisse Setyon é professora na Escola Superior de Propaganda e Marketing de São Paulo (ESPM-SP) e autorizou o uso dessa imagem para fins deste trabalho.
} 
uma vez, cabe ressaltar que a tecnologia empregada nesse cenário está intimamente ligada aos aspectos sociais; humano e não-humano orquestrando redes e conexões que se reconfiguram a todo momento.

Por fim, com esse artigo, esperamos colaborar com os estudos das tecnologias vestíveis no campo da comunicação em suas interfaces com o consumo. Esperamos que esse trabalho inspire outras pesquisas e aguardamos novas e produtivas discussões sobre o tema em ocasiões vindouras.

\section{REFERÊNCIAS}

APPADURAI, Arjun. Disjunção e diferença na economia cultural global. In: FEATHERSTONE, Mike (coord.). Cultura global: nacionalismo, globalização e modernidade. Petrópolis: Vozes, 1999. p.311-327.

BRAGA, José Luiz. O que a Comunicação transforma? In: BRAGA, José Luiz et al. (orgs). Dez perguntas para a produção de conhecimento em comunicação. São Leopoldo: Editora UNISINOS, 2013. p.79-94.

CANCLINI, Néstor García. Consumidores e cidadãos. Rio de Janeiro: UFRJ, 2005

CASTRO, Gisela. Comunicação e consumo nas dinâmicas culturais do mundo globalizado. pragMATIZES - Revista Latino Americana de Estudos em Cultura, Rio de Janeiro, Ano 4, n.6, p. 58-71, mar. 2014.

CASTRO, Gisela. Entretenimento, sociabilidade e consumo nas redes sociais: cativando o consumidor-fã. Revista Fronteiras - Estudos Midiáticos, Porto Alegre, ano 14, n.2, p.133-140, maio/ago. 2012.

DONATI, Luisa Angélica Paraguai. O computador como veste-interface: (re) configurando os espaços de atuação. 2005. 198 f. Tese (Doutorado em Multimeios) - Instituto de Artes, Universidade Estadual de Campinas, Campinas. 2005.

FEATHERSTONE, Mike. Cultura de consumo e pós-modernidade. São Paulo: Studio Nobel, 1995.

GIBSON, William. Neuromancer. São Paulo: Aleph, 2003.

KERCHOVE, Derrick de. Ética de transparência na era do big data. In: LOPES, Maria Immacolata Vassallo; KUNSCH, Margarida Maria Krohling (Orgs.). Comunicação, cultura e mídias sociais. São Paulo: ECA-USP, 2015. p.1-13.

LACERDA, Juciano de Sousa. Caminhos labirínticos para pensar os objetos tecnoinformacionais. In: MALDONADO Alberto Efendy et al. Metodologias de pesquisa em comunicação: olhares, trilhas e processos. Porto Alegre: Sulina, 2011, pp.113-133.

LEMOS, André. A crítica da crítica essencialista da cibercultura. MATRIZes, São Paulo, vol.9, n.1, p. 29-51, jan./jun de 2015.

LEMOS, André. Cibercultura - tecnologia e vida social na cultura. Porto Alegre: Sulina, 2002. 
LÉVY, Pierre. O que é o virtual. Rio de Janeiro: Editora 34, 1996.

McCARTNEY, Scott. ENIAC: the triumphs and tragedies of the world's first computer. Nova York: Berkley Pub Group, 2001.

McCRACKEN, Grant. Cultura \& consumo: novas abordagens ao caráter simbólico dos bens e das atividades de consumo. Rio de Janeiro: Mauad, 2003.

NEJM, Rodrigo. Exposição de si e gerenciamento da privacidade de adolescentes nos contextos digitais. Salvador: Universidade Federal da Bahia, 2016. 267 f. Tese (Doutorado em Psicologia Social) - Programa de Pós-Graduação em Psicologia, Universidade Federal da Bahia, Salvador, 2016.

RETTBERG, Jill Walker. Seeing ourselves through technology: how we use selfies, blogs and wearable devices to see and shape ourselves. Basingstoke: Palgrave Macmillan, 2014.

SASSATELLI, Roberta. Consumer culture: history, theory and politics. London: Sage, 2010.

SCOLARI, Carlos. Hipermediaciones. Elementos para una teoría de la comunicación digital interactiva. Barcelona: Gedisa, 2008.

SLATER, Don. Cultura do consumo \& modernidade. São Paulo: Nobel, 2002.

THE NEW YORK TIMES. Wearable gear and apps to make running healthier, and a lot more Fun. 2014. Disponível em: <http://goo.gl/txg92t>. Acesso em: 1/7/2017.

VERNE, Júlio. Vinte mil léguas submarinas. São Paulo: Penguin/Cia das Letras, 2014.

Original recebido em: 13 de junho de 2017

Aceito para publicação em: 27 de agosto de 2018

Vicente Martin Mastrocola

Professor adjunto da ESPM nos cursos de Sistemas de Informação e de Publicidade e Propaganda. Doutor (2017) em Comunicação e Práticas de Consumo pelo PPGCOM-ESPM, fez sua pesquisa de pós-doutorado na área de advergames na Fakulta Masmédií da Paneurópska Vysoká Skola

(Eslováquia).

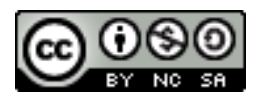

Esta obra está licenciado com uma Licença

Creative Commons Atribuição-NãoComercial-CompartilhaIgual 4.0 Internacional 